\title{
Global Astronomy Month - An Annual Celebration of the Universe
}

\section{Thilina Heenatigala and Mike Simmons}

Astronomers Without Borders

E-mail: thilina.heenatigala@yahoo.com

\begin{abstract}
One of the most successful global outreach efforts in history was the International Year of Astronomy 2009. With the momentum created by this year long program, it was important to take the efforts to coming years. The Astronomers Without Borders organization captured the energy of the International Year of Astronomy 2009 and refocused it as an ongoing annual celebration of the Universe by organizing Global Astronomy Month, a worldwide celebration of astronomy in all its forms, every April. In 2010, the program saw professionals and amateur astronomers, educators and astronomy enthusiasts from around the globe participating together in the spirit of International Year of Astronomy 2009 and provided a global stage for established programs and a framework for partnerships. The 2011 version of the program saw much bigger participation with several global partner organizations joining in creating more than 40 global level programs throughout the month. Within a short period of two years, Global Astronomy Month has evolved to a much needed global platform after International Year of Astronomy 2009.
\end{abstract}

